\title{
REVIEWS
}

\section{A Scoping Review of Frailty and Acute Care in Middle-Aged and Older Individuals with Recommendations for Future Research}

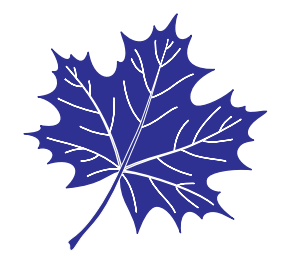

David B. Hogan, MD, FACP, FRCPC ${ }^{1}$, Colleen J. Maxwell $\mathrm{PhD}^{2}$, Jonathan Afilalo, MD, MSc${ }^{3}$, Rakesh C. Arora, $\mathrm{MD}^{4}$, Sean M. Bagshaw, MD, MSc${ }^{5}$, Jenny Basran, $\mathrm{MD}^{6}$, Howard Bergman $\mathrm{MD}^{7}$, Susan E. Bronskill, $\mathrm{PhD}^{8}$, Caitlin A. Carter, HBA, MLIS ${ }^{9}$, Elijah Dixon, MD, MSc ${ }^{10}$, Brenda Hemmelgarn, MD, $\mathrm{PhD}^{11}$, Kenneth Madden, MSc, MD, FRCPC ${ }^{12}$, Arnold Mitnitski, $\mathrm{PhD}^{13}$, Darryl Rolfson, $\mathrm{MD}^{14}$, Henry T. Stelfox, MD, $\mathrm{PhD}^{15}$, Helen Tam-Tham, MSc ${ }^{16}$, Hannah Wunsch, MD, MSc ${ }^{17,18}$

${ }^{1}$ Geriatric Medicine, University of Calgary, Calgary, AB; ${ }^{2}$ Schools of Pharmacy and Public Health \& Health Systems, University of Waterloo, Waterloo, ON; ${ }^{3}$ Division of Cardiology, McGill University, Montreal, QC; ${ }^{4}$ Department of Surgery Anesthesia \& Peri-operative Medicine and Physiology \& Pathophysiology, University of Manitoba, Winnipeg, MB; ${ }^{5}$ Division of Critical Care Medicine, University of Alberta, Edmonton, AB; ${ }^{6}$ Division of Geriatric Medicine, University of Saskatchewan, Saskatoon, SK; ${ }^{7}$ Department of Family Medicine, McGill University, Montréal, QC; ${ }^{8}$ Institute for Clinical Evaluative Sciences, Toronto, ON; ${ }^{9}$ University of Waterloo Library, Waterloo, ON; ${ }^{10}$ Departments of Surgery, Oncology and Community Health Sciences, University of Calgary, Calgary, AB; ${ }^{11}$ Departments of Medicine and Community Health Sciences, University of Calgary, Calgary, AB; ${ }^{12}$ Division of Geriatric Medicine, University of British Columbia, Vancouver, $B C ;{ }^{13}$ Department of Medicine, Dalhousie University, Halifax, NS; ${ }^{14}$ Faculty of Medicine, University of Alberta, Edmonton, $A B ;{ }^{15}$ Department of Critical Care Medicine, University of Calgary, Calgary, AB; ${ }^{16}$ Department of Community Health Sciences, University of Calgary, Calgary, AB; ${ }^{17}$ Department of Critical Care Medicine, Sunnybrook Hospital, Toronto, ON; ${ }^{18}$ Department of Anesthesia, University of Toronto, Toronto, ON, Canada

DOI:https://doi.org/10.5770/cgj.20.240

\begin{abstract}
There is general agreement that frailty is a state of heightened vulnerability to stressors arising from impairments in multiple systems leading to declines in homeostatic reserve and resiliency, but unresolved issues persist about its detection, underlying pathophysiology, and relationship with aging, disability, and multimorbidity. A particularly challenging area is the relationship between frailty and hospitalization. Based on the deliberations of a 2014 Canadian expert consultation meeting and a scoping review of the relevant literature between 2005 and 2015, this discussion paper presents a review of the current state of knowledge on frailty in the acute care setting, including its prevalence and ability to both predict the occurrence and outcomes of hospitalization. The examination of the available evidence highlighted a number of specific clinical and research topics requiring additional study. We conclude with a series of consensus recommendations regarding future research priorities in this important area.
\end{abstract}

Key words: frailty, acute care, hospitalization, outcomes, assessment

\section{INTRODUCTION}

There is general agreement that frailty is a state of increased vulnerability to stressors arising from impairments in multiple body systems leading to declines in homeostatic reserve and resiliency. ${ }^{(1)}$ It is a way to appreciate the variable resilience of older individuals, but unresolved questions persist about its detection, pathophysiology, and relationship with aging, disability, and multimorbidity.

A specific area requiring further study is the complex bidirectional relationship between frailty and admission to hospital. While frailty increases the risk of hospitalization, admission to acute care, in turn, is associated with the development of new or worsening frailty. The latter might be at least partially mediated by the changes in body composition and strength that can occur rapidly during hospital stays. ${ }^{(2)}$ Hospitalizations are a major contributor to the health-care costs associated with frailty ${ }^{(3)}$ and hospital stays represent a dangerous period for vulnerable patients. Frail older patients are particularly susceptible to the adverse consequences of an acute care stay. Compared to more resilient patients they might benefit from a different approach to their care, both during their hospital stay and after discharge, ${ }^{(4)}$ that could decrease

(C) 2017 Author(s). Published by the Canadian Geriatrics Society. This is an Open Access article distributed under the terms of the Creative Commons Attribution Non-Commercial No-Derivative license (http://creativecommons.org/licenses/by-nc-nd/2.5/ca/), which permits unrestricted non-commercial use and distribution, provided the original work is properly cited. 
the personal and societal burden of this health state. The detection of frailty should prompt discussions on treatment preferences with the patient (or surrogate decision maker if the patient lacks capacity) and the advisability of intensive forms of therapy such as admission to an intensive care unit (ICU), surgery, chemotherapy, and invasive cardiac procedures. ${ }^{(5-8)}$ Using the methods described in the next section, we will summarize current knowledge on frailty and acute care. A review of the approaches used to detect frailty is followed by an examination of which ones have been used in acute care, its prevalence in this setting, and the relationship between frailty and risk for either hospitalization or adverse outcomes. A number of specific topics identified in our evaluation of the field are next presented. The paper concludes with a section on the implications of our findings and a series of consensus recommendations regarding research priorities for this important area of inquiry.

\section{METHODS}

This work is based on a prior review on the topic ${ }^{(9)}$, the deliberations of a Canadian Institutes of Health Research (CIHR)-funded invitational expert consultation meeting on Frailty in Acute Care held May 2-3, 2014 in Banff, Alberta (see Appendix A for attendees), and a scoping review ${ }^{(10)}$ of the literature done subsequent to the meeting.

This discussion paper builds on the prior narrative review ${ }^{(9)}$ by updating it and expanding on its scope, methods, and authorship. Laupacis and Straus ${ }^{(11)}$ called for a new type of topic review that would, “... combine the scientific rigor of systematic reviews with the clinically nuanced contextualization and opinion of traditional review articles". We've attempted to incorporate these two approaches in evaluating the available evidence. Other than several trainees, participants of the consultation meeting were clinicians and/or researchers knowledgeable about frailty who collectively could provide the required clinical and scientific expertise. At the consultation meeting participants were asked to share their work on this topic and present their perspective on the identification of frailty and its relationship with hospitalization. Meeting deliberations led to the scheme used for classifying approaches to the detection of frailty and helped identify the research questions to be addressed in the scoping review, as well as number of the key papers to be considered when collating the evidence. Meeting participants were then involved in interpreting the results of the scoping review and creating the recommendations.

For the scoping review of the literature, both PubMed and Ovid EMBASE databases were searched to identify relevant English language articles published between January 2005 and December 2015. The primary objectives of the search were to explore the extent of the evidence base and identify recurring themes and gaps in the literature. The search terms were developed in consultation with a research librarian (C.C.) and are provided in Appendix B. A combination of subject headings and keywords were used. Search terms were modified to meet the requirements of each database and truncation, phrase searching, and adjacency operators were employed where necessary. Identified papers were exported into RefWorks 2.0 (ProQuest, Ann Arbor, MI), an electronic citation management software program, to remove duplicate publications. Two of the authors (D.B.H. and C.J.M.) independently reviewed the identified titles and abstracts. Original research, reviews, and guidelines that dealt with some aspect of frailty and hospitalization of middle-aged and older persons (ages $50+$ years) were selected for full review. They collated and summarized the methods, findings, and/or recommendations of these papers, but did not formally assess their quality. Any areas of disagreement were discussed and mutually resolved. Reference lists were searched for additional relevant publications and papers not otherwise identified that were known to the authors that addressed the relationship between frailty and hospitalization were included in the scoping literature review.

A total of 5,148 papers were initially identified $(1,835$ from PubMed, and 3,313 from Ovid EMBASE). After removal of duplicates, this number was reduced to 3,664. Three hundred and eighty-one articles were selected for full text review, with 248 retained after examination (reasons for exclusion: 51 did not meet inclusion criteria; 70 provided no primary data; 8 were study protocols; and 4 were conference abstracts). Among those retained (note: papers could be allocated to more than one category), 82 papers either described or compared frailty instruments, 27 reported on the prevalence of frailty in acute care settings, and 184 provided data on the ability of frailty to predict hospital admission or the outcomes of a stay. Fewer studies examined the impact of hospitalization on frailty $(\mathrm{n}=12)$, assessed how frailty assessments could help decide on treatment $(n=7)$ or dealt with interventions for frail patients $(\mathrm{n}=15)$. A number of the selected papers reported on specific topics such as the relationships between frailty and delirium $(n=6)$, disability $(n=5)$, geriatric trauma $(n=10)$, ICU admission $(n=10)$, surgery $(n=28)$, oncology $(n=22)$, cardiovascular disease $(n=42)$, chronic kidney disease $(n=$ $8)$, and medications $(\mathrm{n}=16)$. The available literature consisted predominantly of observational studies.

Based on the consultation meeting and scoping review, draft recommendations were developed by two of the authors (D.B.H. and C.J.M.) and refined in an iterative manner until full consensus was achieved on them with all the authors.

\section{DISCUSSION}

\section{Approaches to the Detection of Frailty}

A number of approaches to detection of frailty have been proposed. ${ }^{(12)}$ This reflects the multifaceted nature of frailty in later life, as well as the unique perspective taken by individual researchers. As Heisenberg noted: "What we observe is not nature in itself, but nature exposed to our method of questioning". ${ }^{(13)}$ Two systematic reviews on the detection of 
frailty examined 22 and 27 instruments, respectively, ${ }^{(14,15)}$ and did not identify a preferred measure. Table 1 summarizes the commonly used approaches to the detection of frailty in older adults. The most appropriate one will depend on the specific purpose(s) of the investigator, population being studied, setting, timing of the evaluation, available data, and experience and training of the assessor. In hospitalized patients, frailty determinations are typically based on the actual or estimated status of the person prior to admission in order to avoid being unduly swayed by the transient effects of an acute illness.
Judgment-based measures, including "foot-of-the-bed" assessments, ${ }^{(16)}$ make up the first category. Their validity is based on the belief that clinicians can recognize frailty when they see it. ${ }^{(17)}$ The reliability of these determinations is questionable, with concerns about the influence of the short-term effects of hospitalization and personal biases (e.g., equating frailty with how old the person looks, gender, or slight build). A study of the utility of a quick foot-of-the-bed frailty assessment found only slight to fair agreement (Cohen's kappa statistic $0.0428-0.2558$ ) between it and a more extensive frailty

TABLE 1.

Detection of frailty in acute care settings - a summary of frailty measures

\begin{tabular}{|c|c|c|c|}
\hline Characteristic & $\begin{array}{c}\text { Judgment-based } \\
\text { Measure }\end{array}$ & $\begin{array}{c}\text { Physical Performance } \\
\text { Measure }\end{array}$ & Physical Frailty \\
\hline Description & $\begin{array}{l}\text { Determination of } \\
\text { frailty based on } \\
\text { the judgment of a } \\
\text { clinician }\end{array}$ & $\begin{array}{c}\text { Use of a single } \\
\text { physical performance } \\
\text { measure to categorize } \\
\text { patients }\end{array}$ & $\begin{array}{l}\text { Based on a belief in } \\
\text { a frailty phenotype; } \\
\text { frailty defined as } \\
\text { being present if a } \\
\text { certain number of } \\
\text { criteria are present } \\
\text { (rules based) }\end{array}$ \\
\hline
\end{tabular}

Number of

Items

Examples

Comments

$$
\begin{aligned}
& \text { "Eyeball" or "end-of- } \\
& \text { the-bed" subjective } \\
& \text { assessment; }{ }^{(16,17)} \\
& \text { Subjective Frailty } \\
& \text { Score; }{ }^{(18)} \text { Canadian } \\
& \text { Study of Health } \\
& \text { and Aging (CSHA) } \\
& \text { Clinical Frailty } \\
& \text { Scale }^{(19)}
\end{aligned}
$$

3-5

$$
\begin{aligned}
& \text { Chair stands; } \\
& \text { gait speed; grip } \\
& \text { strength }^{(20-24)}
\end{aligned}
$$

\section{Health Study (CHS) criteria; ${ }^{(15,28)}$ Study of Osteoporosis Fractures (SOF) scale;(29) Survey of Health, Ageing and Retirement in Europe Frailty Index}

Cardiovascular $\left.{ }^{(S H A R E-F I)}\right)^{(31)}$
Quick and easy to perform (though may require equipment); similar to physical frailty; doesn't capture complex impairments may be due to factors other than frailty; many older patients unable to complete testing nature of frailty;
Widely use; results typically reported as frailty category membership (e.g., non-frail, pre-frail, frail) though for some instruments ${ }^{(31)}$ a continuous frailty score can be calculated; criticized for excluding nonphysical domains

Multidimensional Frailty Index
Frailty
Extension of physical frailty to include other dimensions (e.g., cognition, disability/ function, psychological state, morbidities, selfrated health, sensory deficits, social)

$$
5-20
$$

Conselice Study of Brain Aging (CSBA) index; Edmonton Frail Scale; ${ }^{(33)}$

Fatigue, Resistance, Ambulation, and Loss (FRAIL); ${ }^{(34)}$ derived from a standardized comprehensive geriatric assessment (FI-CGA); ${ }^{(36)}$ Frailty Trait Scale (FTS); Gérontopôle Frailty Screening Tool; Groningen Frailty Indicator; ${ }^{(37)}$ Tilburg Frailty Indicator ${ }^{(38)}$

\section{Uncertainty of} which dimensions to include, how to assess and then combine them; scales utilizing different domains identify different sub-groups; with increasing item number becomes similar to frailty index
Criticized as containing too many items leading to issues with feasibility; unclear it has clinically significant advantages to simpler approaches
Frailty Index [FI] (various iterations) $^{(15,44)}$
Assesses the
accumulation of deficits
predisposing to adverse
outcomes; calculated as
total number of items
(deficits) present divided
by maximum potential
number

$30+$

multidimensional frailty assessment 
instrument and fair to substantial correlation (0.2131-0.7281) across the three raters who performed the evaluation. ${ }^{(18)}$ The judgment-based Canadian Study of Health and Aging [CSHA] Clinical Frailty Scale provides descriptions that aid in placing patients on a fitness-to-frailty ordinal scale. ${ }^{(19)}$

The second category is made up of single physical performance measures, such as gait speed, ${ }^{(20)}$ which has been proposed as a practical, objective, and easy-to-interpret measure that accurately predicts important health outcomes. ${ }^{(21)}$ Among community-dwelling seniors, velocities less than $0.8 \mathrm{~m} / \mathrm{sec}$ are associated with higher risks of poor health and death. ${ }^{(22,23)}$ Other gait parameters (e.g., variability, cadence, step width and length, time in double support, dual-task speed) might also be used to detect and grade frailty. ${ }^{(24)}$ These measures are often not possible to obtain on acutely ill patients. Other concerns include the relatively high proportion of older adults with significant cognitive and functional limitations (who many would argue are frail) unable to complete these measures ${ }^{(25,26)}$ and the limited specificity of some of these measures. ${ }^{(27)}$

The third category consists of multidimensional measures of physical frailty, such as the Cardiovascular Health Study (CHS) frailty criteria, ${ }^{(15,28)}$ where frailty is deemed present if the person has three or more of the following five factors: weak grip strength, slow walking speed, low level of physical activity, complaints of fatigue/exhaustion, and unintentional weight loss. This approach has been criticized as solely measuring physical frailty with important domains, such as cognition and mood, not assessed. ${ }^{(1,26)}$ Other composite physical frailty measures include the Study of Osteoporotic Fractures (SOF) frailty index, ${ }^{(29)}$ Short Physical Performance Battery, ${ }^{(30)}$ and SHARE-FI. ${ }^{(31)}$

The fourth category is made up of multidimensional instruments incorporating domains in addition to physical performance. There is general agreement among experts that frailty is multidimensional and may involve cognitive, emotional, social, and/or spiritual aspects, as well as physical components. ${ }^{(32)}$ An example of one of these measures is the Edmonton Frail Scale (EFS), which includes cognition, instrumental activities of daily living (IADL), burden of illness, self-rated health, mood, nutrition, medication issues, incontinence, social support, and mobility. ${ }^{(33)}$ Other examples include FRAIL, ${ }^{(34)}$ Frailty Trait Scale, ${ }^{(35)}$ FI-CGA, ${ }^{\left({ }^{(6)}\right.}$ Groningen Frailty Indicator, ${ }^{(37)}$ and the Tilburg Frailty Indicator, ${ }^{(38)}$ which is based on the work of the Canadian Initiative on Frailty and Aging. ${ }^{(39)}$ These instruments differ in the type and number of domains included, assessed, and weighed leading to the identification of overlapping but distinct subgroups of patients. The decision of which items to include is often based on an underlying conceptualization of frailty though some instruments, like the Changes in Health, End-stage Disease and Symptoms and Signs (CHESS) scale ${ }^{(40)}$ and the Score Hospitalier d'Evaluation du Risque de Perte d'Autonomie (SHERPA) ${ }^{(41)}$ selected items based on how well they predict short-term mortality or functional decline. Some scales developed for other reasons have been repurposed as multidimensional screens for frailty. Examples include the Mini Nutritional Assessment (created as a nutrition screening tool for older patients) ${ }^{(42)}$ and the Program of Research to Integrate the Services for the Maintenance of Autonomy (PRISMA-7) (developed to screen for disabilities). ${ }^{(43)}$

The last category involves the calculation of a frailty index (FI). ${ }^{(15,44)}$ Here 30 or more health "deficits" (i.e., symptoms, signs, diseases, disabilities, and/or laboratory abnormalities) are selected. The items chosen are associated with health status, cover a range of systems, and generally increase, but do not saturate, at older ages. The FI of a person is the ratio of deficits present to the total number considered. For example, if 10 of 40 possible deficits were found in a given person, their FI would be $10 / 40$ or 0.25 . Rather than taking a dichotomized approach (i.e., frailty is present or not), an FI can be treated as a continuous variable allowing one to grade frailty severity. This approach has been criticized for the large number of factors requiring consideration and its mathematical nature. ${ }^{(26)}$ Along with other frailty measures, the FI does not explain how frailty develops or fully inform approaches to its prevention or management. ${ }^{(45)}$

A few points warrant additional comment. The borders between the various approaches are not always clear. The findings of a comprehensive geriatric assessment (CGA) (defined as a multidimensional, interdisciplinary diagnostic process to determine the medical, psychological, and functional capabilities of an older person in order to develop a coordinated and integrated plan for treatment and long-term follow-up) can be used to calculate an FI, derive a multidimensional instrument or make a judgment-based assessment. ${ }^{(19,36,46,47)}$ A number of the multidimensional approaches incorporate almost as many items as you would see with an FI. Another issue is the distinction between frailty and disability. The CSHA Clinical Frailty Scale, a number of the multidimensional instruments (e.g., PRISMA-7), and many FIs include measures of disability in their scoring. Including disability measures in the identification of frailty goes against the belief of many that the two are distinct, though overlapping, concepts. ${ }^{(48)}$ Identifying those requiring help in activities of daily living has been recommended as a practical way of identifying frail patients in hospital, ${ }^{(49)}$ but why call it frailty when you are detecting disability?

Administrative datasets have been explored as a way to identify frailty. They can be used to create a multidimensional instrument or an FI. Additionally, several studies have used claims from a nursing facility or for specific diagnoses (e.g., Alzheimer's disease and other dementias, delirium, Parkinson's disease, stroke, falls, syncope, gait abnormality, fractures, incontinence, dehydration, debility, pressure ulcer, malnutrition and weight loss, and/or failure to thrive) to define the presence of frailty. ${ }^{(50-52)}$ The Johns Hopkins Adjusted Clinical Groups frailty-defining diagnoses indicator (which includes a number of analogous diagnostic categories to the ones previously noted, plus evidence of poverty and/or barriers to 
care) has also been used for this purpose. ${ }^{(53)}$ The prevalence and predictive qualities of seven frailty syndromes (i.e., anxiety $\&$ depression, functional dependence, falls \& fractures, incontinence, mobility problems, pressure ulcers, cognitive impairment [includes delirium, dementia and senility]) based on diagnostic codes abstracted from an administrative data set for hospitals in England have been reported. ${ }^{(54,55)}$ The validity and reliability of approaches largely equating frailty to the presence of particular diagnoses requires additional study.

\section{Frailty in Acute Care}

There is general agreement that frailty affects $20-50 \%$ of older hospitalized patients, with the exact figure influenced by the approach taken for identification and other factors. (56) For example, prevalence ranged from $4 \%$ to $63 \%$ in five studies reporting on frailty among older patients in hospital with cardiac problems. ${ }^{(57-61)}$ Though there were other sources of variability (including significant differences in the age of participants and underlying cardiac conditions), different methods for the detection of frailty were used in these studies. Not all of the approaches described in the preceding section can be or have been used in acute care. In this section we will review which ones have been utilized.

Rarely are patients admitted to hospital with a diagnosis of frailty. An exception would be for elective surgery when the pre-operative assessment includes a search for frailty. Gait speed before surgery has been used as a measure of frailty in older patients about to undergo cardiac surgery. ${ }^{(57,59)}$ Both the Canadian Study of Health and Aging (CSHA) Clinical Frailty Scale and the Cardiovascular Health Study (CHS) frailty criteria based on patient status prior to hospitalization have been successfully used in patients after admission to acute care. A reported version of the EFS, developed for use by non-geriatricians, correlated moderately well with frailty determinations made by geriatricians, could be reliably administered, and predicted outcomes. ${ }^{(62,63)}$ A brief multidimensional frailty battery (i.e., balance measure, Body Mass Index, Trail-Making Test Part B, a depression questionnaire, determination of whether the person lives alone) specifically developed for older patients undergoing cardiac catheterization predicted worsening disability and declines of healthrelated quality of life. ${ }^{(61)}$ Gait speed did not perform as well as balance in this study, and it is noted that balance measures, like one-leg standing, have been suggested as potential frailty markers. ${ }^{(64)}$ Another approach for frailty detection in this setting is using administrative health data (e.g., interRAI assessment system for acute care) to derive an FI. ${ }^{(65)}$

Frailty is a dynamic state with transitions between nonfrail, pre-frail, and frail categories over time. ${ }^{(66-68)}$ Gill et al..$^{(4)}$ reported that the chances of moving from a greater to a lesser degree of frailty were reduced by approximately $50 \%$ with each hospitalization. Less striking effects for hospitalization were seen on the development of more severe degrees of frailty, but it was uncommon to move from the non-frail to a frail state without at least one intervening hospital admission. Data on frailty trajectories during care transitions are otherwise scarce. While transitions across frailty states may be attributable to the health conditions leading to admission, there are hazards associated with hospitalization for older persons. ${ }^{(69)}$ The post-hospital syndrome is an acquired condition of transient heightened vulnerability after hospitalization ${ }^{(70-72)}$ arising from synergistic effects of the presenting problem, comorbidities, and the hospital environment (e.g., immobility, sleep deprivation, polypharmacy, poor nutrition, uncontrolled pain, secondary illnesses, iatrogenic events).

Screening for frailty in acute care should satisfy accepted criteria before wide adoption. ${ }^{(73)}$ Major obstacles to a recommendation for screening include determining what should be done if it is detected, ensuring that harm does not arise from "labelling" a person as frail, and deciding whether, on balance, the cost of case finding is justifiable (see Table 2).

\section{Frailty as a Risk Factor for Hospitalization}

While frailty logically could be predicted to increase the risk of hospitalization, ${ }^{(14)}$ this expected association might be modified by factors such as competing risk of death, substitution effects, and advance care planning. For example, the finding that frail older men residing in assisted living were not more likely than non-frail residents to be hospitalized was potentially due to their high mortality, which led to their removal from being in the "at-risk" pool. ${ }^{(74)}$ Long-term care placement, a common outcome for frail older adults, can lead to a substitution or replacement effect for acute care due to factors such as the availability of nursing care. ${ }^{(75)}$ In a study of end-of-life health-care costs, older adults dying with a frailty trajectory (i.e., slow steady decline during the period before death) had lower hospital but greater long-term care expenditures compared to those where death arose from organ

TABLE 2.

Key questions about the utility and feasibility of frailty assessments in acute care settings

1. Does frailty replace or add significantly to "traditional" risk factors like age, sex, disability, disease severity, and multimorbidity or to standardized and validated risk tools in determining prognosis or facilitating care planning?

2. In what situations or settings does frailty provide actionable information (i.e. specific and credible data that can be used to make recommendations or decisions about interventions)?

3. Is the proposed frailty measure feasible, reliable and valid when administered to acutely ill patients in the fast-paced hospital setting (given that most instruments and frailty indices were initially developed and validated in community samples in stable health)?

4. For acutely ill patients in the hospital, is it possible (or even desirable) to disentangle frailty from the effects of their presenting illness and its treatment? 
failure or a terminal illness. ${ }^{(76)}$ Among older adults with more severe degrees of frailty, a decision may be made to provide care focusing on the relief of symptoms and avoidance of hospitalization. ${ }^{(77)}$ Creating alternatives to hospital-based care for the management of acute illnesses in frail older patients is an area of active development. ${ }^{(78)}$

Most, but not all, studies do indicate that frailty modestly increases the risk of hospitalization. The paper describing the CHS frailty criteria reported that over three years, $33 \%$ of nonfrail study participants were admitted to hospital compared to $43 \%$ for pre-frail and $59 \%$ of frail individuals $(p<.0001)$. While the Women's Health and Aging Study using modified CHS frailty criteria did not find this association, ${ }^{(79)}$ heightened risk was evident in the National Health and Aging Trends Study where overnight hospitalization during the previous 12 months occurred in $11.1 \%$ of non-frail, $22.1 \%$ of pre-frail, and $42.4 \%$ of frail subjects $(p<.001) .{ }^{(80)}$ The increased risk is seen for other approaches to detecting frailty. SOF-defined frailty increased the odds for hospitalization over the next year approximately two-fold (2.08, 95\% CI 1.02-4.24, $p=.045)$. ${ }^{(81)}$ A higher risk of one-year hospitalization was found among older community-dwelling individuals with slow gait speed ( $41 \%$ in those with a gait speed of $<0.6 \mathrm{~m} / \mathrm{sec}$ compared to $26 \%$ for those with a gait speed of 0.6 to $1.0 \mathrm{~m} / \mathrm{sec}$ and $11 \%$ if $>1.0 \mathrm{~m} / \mathrm{sec}, p<.0001){ }^{(82)}$ A higher value on a 30 -item FI based on Canadian Community Health Survey data was associated with significantly increased risks of hospitalization, multiple hospitalizations, and emergency hospitalization over 18 months. ${ }^{\left({ }^{(3)}\right)}$ Frailty has been linked to a higher likelihood of being hospitalized with specific conditions like heart failure ${ }^{(84)}$ and end-stage renal disease. ${ }^{(85)}$

Possibly due to the factors previously noted, the positive association between frailty and subsequent hospitalization tends to be weaker than that seen between it and mortality. ${ }^{(86,87)}$ A similar muted contribution of frailty to predictive models for disability is seen. ${ }^{(88)}$ Relatively few studies have compared frailty measures in their ability to predict hospitalization. The Study of Osteoporotic Fractures (SOF) and CHS criteria had similar abilities in one study, ${ }^{(89)}$ while a multidimensional scale (Conselice Study of Brain Aging Index) performed better than the SOF in another. ${ }^{(90)}$ No significant differences were seen between the CHESS scale, CHS criteria, and two FIs in their ability to predict hospitalization among assisted living residents. ${ }^{(86)}$ It remains uncertain whether a particular approach performs significantly better in this respect.

\section{Frailty and Outcomes of Hospitalization}

Frail patients generally take longer to recover from an acute illness, have longer lengths of hospital stays, are more likely to be discharged to a higher level of care, and are at increased risk of complications and readmission. Following are some examples.

Older patients hospitalized with a myocardial infarction who were frail based on the CSHA Clinical Frailty
Scale had a significantly longer average length of stay with higher risks for in-hospital and one-month mortality and a composite outcome consisting of death, re-infarction, re-vascularization procedure, re-hospitalization, major bleeding, cerebrovascular disease, and/or need for dialysis. (91) Slow gait speed was associated with an increased risk of a prolonged postoperative stay and a higher likelihood of mortality, major morbidity, and/or discharge to a healthcare facility after cardiac surgery. ${ }^{(57)}$ Patients with frailty based on modified CHS criteria had longer lengths of stay after both minor and major surgical procedures, experienced higher rates of post-operative complications, and were more likely to be discharged to an assisted living facility. ${ }^{(58)}$ Older surgical patients with increasing levels of frailty identified with the EFS had longer lengths of stay, more post-operative complications, and a lower likelihood of being discharged home. ${ }^{(92)}$ Frailty based on a multidimensional instrument was associated with a higher likelihood of death and institutional discharge, as well as greater health-care costs. ${ }^{(93-95)}$ In an Australian study of older people hospitalized with an acute illness, the CSHA Clinical Frailty Scale predicted in-hospital mortality, new nursing home placement, and a longer hospital stay, ${ }^{(96)}$ while a UK study found that a modified CSHA Clinical Frailty Scale (i.e., 9-point version) in adjusted analyses was an independent predictor of in-patient mortality, transfer to the geriatric service, and a length of stay of 10 or more days. ${ }^{(97)}$ Another study using the 9-point version of the scale reported that moderate to severe frailty was an independent predictor of readmission to hospital or death within 30 days of discharge (adjusted OR 2.19, 95\% CI 1.12-4.24). ${ }^{(98)}$

\section{Specific Topics}

A number of specific clinical and research areas within the examined literature were identified and are summarized below.

\section{Delirium}

Delirium is a common and serious complication for hospitalized older patients. ${ }^{(99)}$ Most, but not all, studies indicate that frail older hospitalized patients are more likely to develop delirium. Two studies reported an increased risk of developing postoperative delirium. ${ }^{(100,101)}$ A third one that dealt with patients seen by a geriatric medicine service suggested frailty increased the likelihood of not fully recovering from a delirium. ${ }^{(102)}$ While a recent paper found that physical frailty was not a risk factor for delirium in older patients admitted to an acute geriatric ward, ${ }^{(103)} \mathrm{a}$ prospective observational study of elective cardiac surgery patients reported that frailty (whether identified by a physical performance measure, modified CHS criteria, or an FI) was associated with a 3-to 8-fold increase in the risk of post-operative delirium. ${ }^{(104)}$ It has been speculated that there is a mutually reinforcing adverse relationship between the two with frailty predisposing to delirium and delirium decreasing the likelihood of fully recovering. ${ }^{(105)}$ 


\section{Disability}

In older persons, hospitalization increases the likelihood of developing new or worsening disability. ${ }^{(106)}$ It was initially unclear whether frail patients showed greater functional decline, ${ }^{(107)}$ but Boyd et al. ${ }^{(108)}$ reported that the development of increasing ADL dependency after hospitalization was more likely among those with pre-existing frailty based on CHS criteria. Gill and colleagues ${ }^{(66)}$ also found that the likelihood of "transitioning" from none to mild disability within a month of hospitalization was $34.9 \%$ (95\% CI, 34.5\%-35.3\%) for physically frail individuals compared to $4.9 \%(95 \% \mathrm{CI}$, $4.7 \%-5.1 \%$ ) among non-frail ones. Functional decline from pre-admission status at the time of hospital discharge has also been used to retrospectively diagnose frailty in older patients. ${ }^{(109,110)}$ A study that tracked mobility in older patients during their hospital stays found that those with higher scores on an FI had slower rates of recovery. ${ }^{(111)}$

\section{Geriatric Trauma}

Frailty has been used to examine the heterogeneity of older patients who experience significant trauma. ${ }^{(112)}$ An FI independently predicted in-hospital complications (odds ratio [OR] 2.5, 95\% CI 1.5-6.0, $p=.001)$, discharge to a skilled nursing facility or death in hospital (for the latter two outcomes combined the OR was $1.6,95 \%$ CI 1.1-2.4, $p=.001$ ). $(113,114)$ The same investigators reported that a 15 -item frailty scale was an independent predictor in adjusted analysis of discharge to a skilled nursing facility or death. ${ }^{(115)}$ Among older patients admitted after ground-level falls, frailty (identified by an FI of 0.25 or greater) in multivariate analyses identified patients more likely to have fractures (OR 1.8, 95\% CI 1.2-2.3) and be discharged to a facility (OR 1.42, 95\% CI 1.08-3.09). ${ }^{(116)}$ Frailty assessments might have a role in targeting patients for a CGA and in anticipating the discharge needs of these patients.

\section{Intensive Care Units}

Utilization of ICUs by very old (aged 80+ years) patients is rising. ${ }^{(117)}$ Their probability of surviving and returning to baseline levels of functioning at one year after ICU admission is approximately $26 \%{ }^{(118)}$ Pre-ICU frailty assessments have attracted interest as a potential prognostic factor. ${ }^{(119)}$ Bagshaw et al. ${ }^{(120)}$ reported a $32.8 \%$ prevalence of frailty based on the CSHA Clinical Frailty Scale in critically ill patients aged 50+ years. In adjusted analyses, both in-hospital and one-year mortality were higher among frail patients. They were also more likely to suffer major adverse consequences, become functionally dependent, report a lower quality of life, and be readmitted to hospital in the 12 months following presentation. In another multicenter study of older ICU patients, the prevalence of frailty based on different approaches ranged from 23-41\%. ${ }^{(121)}$ In this study the CSHA Clinical Frailty Scale out-performed modified CHS criteria in predicting hospital and six-month mortality. Judgment-based determinations of pre-morbid status like the CSHA Clinical Frailty Scale are appealing for this population. ${ }^{(5)}$ It may also be feasible to derive an FI utilizing routinely collected data on these patients as shown in a study where an FI constructed from variables drawn from ICU admission records was strongly associated with likelihood of survival. ${ }^{(122)}$ While frailty assessments can be used to frame the expectations of both patients and their families, it seems premature to advocate their use in decision-making about the withdrawal of treatment. ${ }^{(121,123)}$

\section{Surgery}

Frailty has attracted interest as a predictor of surgical outcomes. ${ }^{(6,124)}$ As examples, a frailty scale based on a comprehensive geriatric assessment (CGA) performed before surgery predicted postoperative one-year all-cause mortality and discharge to a nursing facility in adjusted analyses, ${ }^{(125)}$ while a 5-point frailty risk score based on two components of CHS criteria (weight loss, grip strength), American Society of Anesthesiologists (ASA) scale score, and hemoglobin, predicted 30-day post-operative complications. ${ }^{(126)}$ In the future, frailty assessments might be used to tailor the anesthetic and surgical (including deciding whether to operate) approach taken, counsel patients about likely outcomes, and trigger the implementation of select preoperative (e.g. physical therapy, nutritional supplements) and perioperative (e.g., team-based pathways, delirium prevention) interventions. ${ }^{(124)}$

\section{Oncology}

In the near future, persons 65 years of age and older are projected to account for $70 \%$ of all cancer diagnoses. ${ }^{(127)}$ Older persons with a non-skin cancer appear to have a higher prevalence of frailty compared to those without such a history. (128) The mechanisms underlying this relationship are unclear, but both cancer and frailty have common manifestations. Symptoms such as weight loss and fatigue, which are felt to be clinical markers of frailty, become common during the later stages of cancer. Cachexia associated with cancer and other chronic diseases and age-related sarcopenia represent two distinct muscle wasting conditions that lead to declines in muscle mass, strength, and function. ${ }^{(129,130)}$ Research is needed to better understand these two processes, how they overlap and interact, and what can be done to counteract them. It is also possible that cancer and its treatment could lead to frailty. Childhood cancer survivors might be predisposed to frailty from the toxic effects on normal tissue of the multimodal therapy used to treat their malignancy. The prevalence of frailty based on modified CHS criteria among these survivors was equivalent to cohorts about 30 years older and associated with an increased risk of death. ${ }^{(131)}$ A research priority in geriatric oncology is the identification of vulnerable patients who superficially appear healthy enough for aggressive forms of therapy yet are at high risk of decompensation. ${ }^{(7)}$ Better delineation of this group could inform the choice of treatment options, though additional work on this is clearly needed. In a pilot study of patients newly diagnosed with cancer, frailty markers were common but did not predict subsequent 
health-care utilization, ${ }^{(132)}$ though weak grip strength was associated with developing severe treatment toxicity. ${ }^{(133)}$

\section{Cardiovascular Disease}

The relationship between frailty and cardiovascular disease might be due to common causal pathways such as chronic low-grade inflammation and insulin resistance. ${ }^{(8)}$ In addition to the methods previously described, other approaches for identifying frailty in this patient population have been utilized such as the Comprehensive Assessment of Frailty test, ${ }^{(134)}$ an abridged version called Frailty predicts death One yeaR after Elective Cardiac Surgery Test (FORECAST) that consists of timed chair stands, self-reported weakness, and ability to climb stairs, the CSHA Clinical Frailty Scale, and serum creatinine, ${ }^{(135)}$ and an FI measure. ${ }^{(136)}$ Preoperative gait speed and the CSHA Clinical Frailty Scale have attracted the greatest interest in this patient population. Information of frailty status could be used to both predict risk and possibly direct therapy. ${ }^{(8,137,138)}$ The benefit of tailoring therapy based on a frailty determination awaits verification, but it holds promise as a means of improving the care provided to vulnerable patients. ${ }^{(139)}$

\section{Chronic Kidney Disease}

The prevalence of frailty in patients with chronic kidney disease (CKD) not currently on dialysis therapy has been studied primarily with modified CHS criteria. Patients, even at an early stage of renal dysfunction (i.e., CKD stage 1 or 2 ), have an approximately 2 -fold higher risk of frailty with the likelihood of frailty rising with worsening renal function. (140) Frailty is associated with worse outcomes in patients with CKD. There is an approximately 2 -fold increased risk of mortality or dialysis in older patients with renal impairment after adjusting for potential confounders. ${ }^{(140)}$ Frailty affects about three-quarters of patients starting dialysis ${ }^{(141)}$ and is associated with higher estimated glomerular filtration rate (eGFR) at initiation (possibly because frailty symptoms are confused with those of uremia, eGFR in the setting of low muscle mass overestimates true GFR [meaning initiation at the higher eGFR is appropriate], and/or greater willingness of frail patients to start dialysis). After initiation of dialysis, frail patients have a greater likelihood of dying or being hospitalized. Frailty might be a factor for consideration when deciding on a non-dialytic or conservative approach in patients with advanced CKD. ${ }^{(142)}$ Research suggests that frailty might be at least partially reversible in this patient population. Among recipients of a kidney transplant who met CHS criteria for frailty, nearly three-quarters were non- or intermediately frail three months post-procedure. ${ }^{(143)}$

\section{Medications}

Polypharmacy (use of multiple medications) is common among frail persons, ${ }^{(144-147)}$ as is the use of sedating or anticholinergic drugs. ${ }^{(148-150)}$ Observational studies show an association between all three and the subsequent development of frailty. ${ }^{(146,148,151)}$ While they show changes in distribution, binding, metabolism, transport, and/or elimination of pharmaceuticals, ${ }^{(152-157)}$ frail individuals can still benefit from pharmacotherapy. Secondary analysis of HYpertension in the Very Elderly Trial (HYVET) data found no evidence of an interaction between treatment effect and an FI. ${ }^{(158)}$ The complicated benefit/risk analyses with pharmacotherapy of frail patients were shown by a study on antithrombotic therapy in older hospitalized patients with atrial fibrillation. ${ }^{(159)}$ Compared to non-frail patients, those with frailty were less likely to be discharged on warfarin $(p<.0001)$, more likely to have a cardioembolic stroke within six months $(12.3 \%$ vs. $3.9 \%, p<.05)$, and showed a non-significant trend for more major or severe hemorrhages $(23.0 \%$ vs. $16.9 \%, p=.29)$. While oral anticoagulants may offer the best hope of stroke prevention, this has to be tempered by a possible increase in bleeding risk and a narrowing of the therapeutic window. ${ }^{(160)}$ Medications (e.g., angiotensin converting enzyme inhibitors, vitamin $\mathrm{D}$, anabolic hormones, ghrelin) have been considered as potential therapies for frailty. ${ }^{(161,162)}$

\section{Implications for Clinical Care and Research}

Multiple observational studies have shown that frailty (however defined) is associated with adverse outcomes. Additional observational studies solely demonstrating this would be redundant. While there is still a requirement for studies comparing alternative approaches to detecting frailty, the more pressing research needs are in confirming the clinical utility of frailty in counselling patients and developing effective interventions that prevent, slow progression, or reverse frailty.

Patients with frailty, especially at a more severe stage, are arguably less likely to benefit from intrusive forms of therapy and can be reasonably advised to consider a less aggressive course of action. ${ }^{(163)}$ While the detection of frailty should trigger person-centred discussions, ${ }^{(43)}$ caution must be exercised in using frailty as the sole reason to withhold potentially beneficial forms of therapy. ${ }^{(164)}$ While it has been suggested that "frailty" is a euphemism for patients who are terminally ill, ${ }^{(165)}$ frailty may not progress in the short term and, in select cases, may be reversible. ${ }^{(43,143)}$ The possibility of modifiable contributors should always be considered. Accurate information on the relative benefits and risks (including burden) of available therapies is needed for informed decision-making. ${ }^{(43,166)}$ Even if associated with higher mortality, an aggressive approach may still be preferred if it offers the best hope for "success" as defined by the patient. Symptom control, independence, and quality of life may be of greater relevance to them than mortality.

Adding frailty to characteristics like age, sex, multimorbidity, and scores on select scales ${ }^{(167,168)}$ increases the areas under receiver operating characteristic (ROC) curves for predicting patient outcomes, but the gains are modest. ${ }^{(58,74,82)}$ There is still debate about the clinical utility of frailty assessments ${ }^{(87,169,170)}$ and uncertainty as to whether it adds significantly to the prog- 
nostic abilities of multimorbidity and/or disability measures. For example, Aarts et al. ${ }^{(171)}$ found that while CHS criteria defined frailty was associated with an increased risk of both death and institutionalization, this risk was limited to those who also had multimorbidity and/or disability. In a second study, Ferrante and colleagues ${ }^{(172)}$ assessed the "functional trajectories" (based on a count of basic, instrumental, and mobility disabilities) of older patients who had at least one ICU admission. Compared to those with minimal pre-ICU disability, patients with mild-to-moderate and severe pre-existing disability had more than double and triple the risk respectively of dying within a year. Physical frailty based on gait speed was not a significant contributor to mortality risk in adjusted analyses.

Recommendations for the management of frail older patients in hospital ${ }^{(173,106)}$ include CGA (the "gold standard for the management of frailty in older people"), ${ }^{(4)}$ tailored interventions provided in a defined physical environment (e.g., Acute Care for Elders [ACE] units), careful attention to hospitalization processes (e.g., early mobilization, attentive continence care, maintenance of nutrition, careful use of medications), screening for common problems (e.g., delirium), and/or pro-active discharge planning. While the utility of CGA is supported by the literature, ${ }^{(174)}$ its effects (and those of other in-hospital interventions) are modest. ${ }^{(175)}$ A number of these interventions, such as early mobilization, would be indicated for all patients though frail ones may be more vulnerable to suboptimal care. While no relationship was found between a measure of higher quality of care while in hospital and the likelihood of functional decline after discharge in one study, ${ }^{(176)}$ it would be reasonable to target modifiable hospitalization risk factors for functional decline in the care of frail patients. ${ }^{(177)} \mathrm{A}$ fundamental change in the structure and processes of the care provided in hospital ${ }^{(178)}$ and/or novel therapeutics are needed to have a substantive impact. Unfortunately few interventions for frailty have been or are being rigorously studied at this time. ${ }^{(179,180)}$

Avoiding admission or decreasing exposure to the hazards of hospitalization by earlier discharges would complement in-hospital approaches. ${ }^{(181-184)}$ Improved coordination of services and shifting resources to the community could lead to fewer hospital admissions and more efficient use of acute care services. ${ }^{(3)}$ An intriguing finding in hospital-at-home trials has been a lower incidence of delirium among treated patients $^{(185-188)}$ - delirium rates are proposed as a way to monitor the quality of hospital care for older patients. ${ }^{189)}$ "Reactivating" frail patients after hospitalization represents another promising approach. ${ }^{(190)}$

Although based on the deliberations of a diverse team of clinical and health researchers, this work reflects the opinion of a group of individuals predominantly from one country. Much of what we state may seem self-evident, and others may feel stronger opinions could have been expressed. Our desire, though, was to stimulate discussion about the relationship between frailty and hospitalization. We feel the incomplete and evolving nature of the field justify our qualified position on these matters. Table 3 summarizes our consensus recom- mendations for research on frailty and acute care. This is not a comprehensive listing of all the important unanswered questions about frailty but reflect those topics that arose in our discussions. We feel the items listed in Table 3 and other work are required before we can achieve a fuller understanding of the how the recognition and management of frailty could improve both the utilization of hospital care by vulnerable populations and, most importantly, their outcomes.

\section{ACKNOWLEDGEMENTS}

The authors wish to acknowledge the other participants involved in the Frailty in Acute Care Canadian Institutes of Health Research (CIHR) Planning Meeting (May 2-3, 2014),

TABLE 3.

Research priorities for frailty and acute care

1. A systematic review should be undertaken to determine whether older hospitalized patients should be screened for frailty. While frailty is associated with a higher risk of both admission to hospital and adverse consequences arising during the stay, the clinical utility of its detection is uncertain. Such a review should consider both the positive and the negative aspects of detecting frailty. Our scoping review indicates that there is sufficient literature for this.

2. Additional evaluation of frailty measures is required to more fully understand their respective advantages and disadvantages in a hospital setting. The choice of the frailty measure used in a research study should be primarily based on the aim or intention of the investigators, specifics of the population being studied, psychometric qualities of the instrument, and questions of feasibility and respondent burden. ${ }^{(191)}$

3. The relationship between frailty and the post-hospital syndrome should be explored.

4. Studies of frailty trajectories and outcomes should consider the potential modifying effect of psychosocial factors. ${ }^{\text {(192) }}$

5. There is an urgent need to develop and evaluate interventions that will allow frail older patients to safely avoid hospitalization and/or receive improved care once admitted. Hospital-based interventions should minimize adverse consequences and promote recovery to the greatest extent possible both during and after hospitalization. A wide range of approaches should be considered including exercise/ physical activity, nutritional supplements, pharmaceutical agents, multidimensional interventions, and health system innovations. This will require the investment of targeted research funds.

6. Further work is needed on exploring interventions to prevent the development and/or progression of frailty. This holds the greatest potential of benefit at a population level.

7. An interdisciplinary, intersectoral (i.e., community, acute care, long-term care) research network on frailty that meaningfully involves patients and families should be supported. 
see Appendix A. This work was supported by a Canadian Institutes of Health Research - Institute of Aging (CIHR-IA) Planning Grant entitled, "Emerging research and clinical priorities in the detection and management of frailty in older patients across acute care settings" (Reference Number HLA129620). www.cihr-irsc.gc.ca

\section{CONFLICT OF INTEREST DISCLOSURES}

The authors declare that no conflicts of interest exist.

\section{REFERENCES}

1. Bergman H, Ferrucci L, Guralnik J, et al. Frailty: an emerging research and clinical paradigm - issues and controversies. $J$ Gerontol A Biol Sci Med Sci. 2007;62(7):731-37.

2. Alley DE, Koster A, Mackey D, et al. Hospitalization and change in body composition and strength in a population-based cohort of older people. J Am Geriatr Soc. 2010;58(11):2085-91.

3. Béland F, Bergman $\mathrm{H}$, Lebel L, et al. Integrated services for frail elders (SIPA): a trial of a model for Canada. Can J Aging. 2006;25(1):25-42.

4. Gill TM, Gahbauer EA, Han L, et al. The relationship between intervening hospitalizations and transitions between frailty states. J Gerontol A Biol Sci Med Sci. 2011;66(11):1238-43.

5. McDermid RC, Stelfox HT, Bagshaw SM. Frailty in the critically ill: a novel concept. Critical Care. 2011;15:301.

6. Brown NA, Zenilman ME. The Impact of Frailty in the Elderly on the Outcome of Surgery in the Aged. Adv Surg. 2010;44(1):239-49.

7. Exterman M, Aapro M, Audiso R, et al. Main priorities for the development of geriatric oncology: a worldwide expert perspective. J Geriatr Oncol. 2011;2(4):270-73.

8. Afilalo J. Frailty in patients with cardiovascular disease: why, when, and how to measure. Curr Cardiovasc Risk Rep. 2011;5:467-72.

9. Hogan DB, Maxwell CJ. Fragilitié, hospitalisation, et capacité de supporter les traitements médicaux intensifs. En: La fragilitié des personnes âgées: définitions, controverses et perspectives d'action (sous la direction de Francois Béland et Hervé Michel). Rennes Cedex, France: Presses de l'Ecole des Hautes Etudes en Santé Publiques; 2013.(p. 105-21).

10. Armstrong R, Hall BJ, Doyle J, et al. 'Scoping the scope' of a Cochrane review. J Public Health. 2011;33(1):147-50.

11. Laupacis A, Straus S. Systematic Reviews: Time to address clinical and policy relevance as well as methodological rigor. Ann Intern Med. 2007;147:273-74.

12. Hogan DB, MacKnight C, Bergman H. Models, definitions and criteria of frailty. Aging Clin Exp Res. 2003;15 (Suppl 3):3-29.

13. Heisenberg W. Physics and philosophy: the revolution in modern science. NY: Harper \& Rowe; 1958, p. 32.

14. Sternberg SA, Schwartz AW, Karunananthan S, et al. The identification of frailty: a systematic literature review. $J \mathrm{Am}$ Geriatr Soc. 2011;59(11):2129-38.

15. Bouillon K, Kivimaki M, Hamer M, et al. Measures of frailty in population-based studies: an overview. BMC Geriatr. 2013;13:64.
16. Hubbard RE, Story DA. Patient frailty: the elephant in the operating room. Anaesthesia. 2014;69(Suppl 1):26-34.

17. Speir A. Defining frailty: "I know it when I see it." $J$ Thorac Cardiovasc Surg. 2015;149(3):875-76.

18. Hii TBK, Lainchbury JG, Bridgman PG. Frailty in acute cardiology: comparison of a quick clinical assessment against a validated frailty assessment tool. Heart Lung Circ. 2015, 24: $551-56$

19. Rockwood K, Song X, MacKnight C, et al. A global clinical measure of fitness and frailty in elderly people. CMAJ. 2005;173(5):489-95.

20. Gill TM, Baker DI, Gottschalk M, et al. A program to prevent functional decline in physically frail, elderly persons who live at home. N Engl J Med. 2002;347:1068-74.

21. Cesari M. Role of gait speed in the assessment of older patients. JAMA. 2011;305(1):93-94.

22. Studenski S, Perera S, Patel K, et al. Gait speed and survival in older adults. JAMA. 2011;305(1):50-58.

23. Stanaway FF, Gnjidic D, Blyth FM, et al. How fast does the Grim Reaper walk? Receiver operating characteristics curve analysis in healthy men aged 70 and over. BMJ. 2011;343:d7679.

24. Schwenk M, Howe C, Saleh A, et al. Frailty and technology: a systematic review of gait analysis in those with frailty. Gerontology. 2014;60(1):79-89.

25. Rockwood K, Jones D, Wang Y, et al. Failure to complete performance-based measures is associated with poor health status and an increased risk of death. Age Ageing. 2007;36(2):225-28

26. Hubbard RE, O'Mahony MS, Woodhouse KW. Characterising frailty in the clinical setting - a comparison of different approaches. Age Ageing. 2009;38(1):115-19.

27. Clegg A, Rogers L, Young J. Diagnostic test accuracy of simple instruments for identifying frailty in community-dwelling older people: a systematic review. Age Ageing. 2015;44(1):148-52.

28. Fried LP, Tangen CM, Walston J, et al. Cardiovascular Health Study Collaborative Research Group.: frailty in older adults: evidence for a phenotype. J Gerontol Biol Sci Med Sci. 2001;56(3):M146-M157.

29. Ensrud KE, Ewing SK, Taylor BC, et al. Comparison of 2 frailty indexes for prediction of falls, disability, fractures and death in older women. Arch Intern Med. 2008;168(4):382-89.

30. Fisher S, Ottenbacher KJ, Goodwin JS, et al. Short physical performance battery in hospitalized older adults. Aging Clin Exp Res. 2009;21(6):445-52.

31. Romero-Ortuno R, Walsh CD, Lawlor BA, et al. A frailty instrument for primary care: findings from the Survey of Health, Ageing and Retirement in Europe (SHARE). BMC Geriatr. 2010;10:57.

32. Rodriguez-Manas L, Feart C, Mann G, et al. Searching for an operational definition of frailty: a Delphi method based consensus statement. The Frailty Operative Definition-Consensus Conference Project. J Gerontol A Biol Sci Med Sci. 2013;68(1):62-67.

33. Rolfson DB, Majumdar SR, Tsuyuki RT, et al. Validity and reliability of the Edmonton Frail Scale. Age Ageing. 2006;35(5):526-29. 
34. Morley JE, Vellas B, Abellan van Kan G, et al. Frailty consensus: a call to action. J Am Med Dir Assoc. 2013;14(6):392-97.

35. García-García FJ, Carcaillon L, Fernandez-Tresguerres J, et al. A new operational definition of frailty: the Frailty Trait Scale. J Am Med Dir Assoc. 2014;15(5):371.e7-371.e13.

36. Jones DM, Song X, Rockwood K. Operationalizing a frailty index from a Standardized Comprehensive Geriatric Assessment. J Am Geriatr Soc. 2004;52(11):1929-33.

37. Peters LL, Boter H, Buskens E, et al. Measurement properties of the Groningen Frailty Indicator in home-dwelling and institutionalized elderly people. J Am Med Dir Assoc. 2012;13(6):546-51.

38. Gobbens RJJ, van Assen MALM, Luijkx KG, et al. The Tilburg Frailty Indicator: psychometric properties. $\mathrm{J} \mathrm{Am} \mathrm{Med} \mathrm{Dir} \mathrm{Assoc.}$ 2010;11(5):344-55.

39. Gobbens RJJ, van Assen MALM, Luijkx KG, et al. The Predictive validity of the Tilburg Frailty Indicator: disability, health care utilization, and quality of life in a population at risk. Gerontologist. 2012;52(5):619-31.

40. Hirdes JP, Frijters DH, Teare GF. The MDS-CHESS Scale: A new measure to predict mortality in institutionalized older people. J Am Geriatr Soc. 2003;51(1):96-100.

41. Cornette P, Swine C, Malhomme B, et al. Early evaluation of the risk of functional decline following hospitalization of older patients: development of a predictive tool. Eur J Pub Health. 2006;16(2):203-08.

42. Dent E, Visvanathan R, Piantadosi C, et al. Use of the Mini Nutritional Assessment to detect frailty in hospitalised older people. J Nutr Health Aging. 2012;16(9):764-67.

43. Fit for Frailty - consensus best practice guidance for the care of older people living in community and outpatient settings. A report from the British Geriatrics Society. London, UK: Br Geriatrics Soc.; 2014. Available from: http://www.bgs.org. uk/campaigns/fff/fff_full.pdf

44. Searle SD, Mitnitski A, Gahbauer EA, et al. A standard procedure for creating a frailty index. BMC Geriatr. 2008;8:24.

45. Waltson JD, Bandeen-Roche K. Frailty: a tale of two concepts. BMC Med. 2015;13:185.

46. Evans SJ, Sayers M, Mitnitski A, et al. The risk of adverse outcomes in hospitalized older patients in relation to a frailty index based on a comprehensive geriatric assessment. Age Ageing. 2014;43(1):127-32.

47. Goldstein J, Hubbard RE, Moorhouse P, et al. The validation of a care partner-derived frailty index based upon comprehensive geriatric assessment (CP-FI-CGA) in emergency medical services and geriatric ambulatory care. Age Ageing. 2015;44(2):327-30.

48. Fried LP, Ferrucci L, Darer J, et al. Untangling the Concepts of Disability, Frailty, and Comorbidity: Implications for Improved Targeting and Care. J Gerontol A Biol Med Sci. 2004;59(3):255-63.

49. Royal College of Physicians. Acute care toolkit 3-Acute medical care for frail older people. London, UK: Royal College of Physicians; 2012. Accessed November 23, 2015. Available from: https://www.rcplondon.ac.uk/guidelines-policy/acutecare-toolkit-3-acute-medical-care-frail-older-people
50. Lunney JR, Lynn J, Hogan C. Profiles of older medicare decedents. J Am Geriatr Soc. 2002;50(6):1108-12.

51. Lunney JR, Lynn J, Foley DJ, et al. Patterns of functional decline at the end of life. JAMA. 2003;289(18):2387-92.

52. Hope AA, Gong MN, Guerra C, et al. Frailty before critical illness and mortality for elderly medicare beneficiaries. $J \mathrm{Am}$ Geriatr Soc. 2015;63(6):1121-28.

53. McIsaac DI, Bryson GL, van Walraven C. Association of frailty and 1-year postoperative mortality following major elective noncardiac surgery - a population-based cohort study. JAMA Surg. 2016;151(6):538-45. Epub 2016 January 20.

54. Soong J, Poots AJ, Scott S, et al. Quantifying the prevalence of frailty in English hospitals. BMJ Open. 2015;5(10): e0008456.

55. Soong J, Poots AJ, Scott S, et al. Developing and validating a risk prediction model for acute care based on frailty measures. BMJ Open. 2015;5(10):e008457.

56. Parker SG, Fadayevatan R, Lee SD. Acute hospital care for frail older people. Age Ageing. 2006;35(6):551-52.

57. Afilalo J, Eisenberg MJ, Morin J-F, et al. Gait speed as an incremental predictor of mortality and major morbidity in elderly patients undergoing cardiac surgery. J Am Coll Cardiol. 2010;56(20):1668-76.

58. Makary MA, Segev DL, Pronovost PJ, et al. Frailty as a predictor of surgical outcomes in older patients. J Am Coll Surg. 2010;210(6):901-08.

59. Purser JL, Kuchibhatla MN, Fillenbaum GG, et al. Identifying frailty in hospitalized older adults with significant coronary artery disease. J Am Geriatr Soc. 2006;54(11):1674-81.

60. Lee DH, Buth KJ, Martin B-J, et al. Frail patients are at increased risk for mortality and prolonged institutional care after cardiac surgery. Circulation. 2010;121:973-78.

61. Freiheit EA, Hogan DB, Eliasziw M, et al. Development of a frailty index for patients with coronary artery disease. $\mathrm{J} \mathrm{Am}$ Geriatr Soc. 2010;58(8):1526-31.

62. Hillmer SN, Perera V, Mitchell S, et al. The assessment of frailty in older people in acute care. Australasian J Ageing. 2009;28(4):182-88.

63. Rose M, Pan H, Levinson MR, et al. Can frailty predict complicated care needs and length of stay? Intern Med J. 2014;44(8):800-05.

64. Michikawa T, Nishiwaki Y, Takebayashi T, et al. Oneleg standing test for elderly populations. J Orthop Sci. 2009;14(5):675-85.

65. Hubbard RE, Peel NM, Samanta M, et al. Derivation of a frailty index from the interRAI acute care instrument. BMC Geriatr. 2015;15:27.

66. Gill TM, Allore HG, Gahbauer EA, et al. Change in disability after hospitalization or restricted activity in older persons. JAMA. 2010;304(17):1919-28.

67. Gill TM, Gahbauer EA, Allore HG, et al. Transitions between frailty states among community-living older persons. Arch Intern Med. 2006;166(4):418-23.

68. Xue QL. The Frailty Syndrome: definition and natural history. Clin Geriatr Med. 2011;27(1):1-15.

69. Creditor MC. Hazards of hospitalization of the elderly. Ann Intern Med. 1993;118(3):219-23. 
70. Krumholz HM. Post-Hospital Syndrome-an acquired, transient condition of generalized risk. $N$ Engl J Med. 2013;368(2):100-02.

71. Detsky AS, Krumholz HM. Reducing the trauma of hospitalization. JAMA. 2014;311(21):2169-70.

72. Dharmarajan K, Hsieh AF, Kulkarni VT, et al. Trajectories of risk after hospitalization for heart failure, acute myocardial infarction, or pneumonia: retrospective cohort study. BMJ. 2015;350:h411.

73. Wilson JMG, Jungner G. Principles and practice of screening for disease. World Health Organization Papers (No. 34). Geneva: WHO; 1968.

74. Freiheit EA, Hogan DB, Strain L, et al. Operationalizing frailty among older residents of assisted living facilities. BMC Geriatr. 2011;11:23.

75. Wilson DM, Truman CD. Evaluating institutionalization by comparing the use of health services before and after admission to a long-term-care facility. Eval Health Prof. 2004;27(3):219-36.

76. Fassbender K, Fainsinger RL, Carson M, et al. Cost trajectories at the end of life: the Canadian experience. J Pain Symptom Manage. 2009;38(1):75-80.

77. Boockvar KS, Meier DE. Palliative care for frail older adults: "There are things I can't do anymore that I wish I could . . " JAMA. 2006;296(18):2245-53.

78. Gillick MR. When frail elderly adults get sick: alternatives to hospitalization. Ann Intern Med. 2014;160(3):201-02.

79. Bandeen-Roche K, Xue QL, Ferrucci L, et al. Phenotype of frailty: characterization in the women's health and aging studies. J Gerontol A Biol Sci Med Sci. 2006;61(3):262-66.

80. Bandeen-Roche K, Seplaki CL, Huang J, et al. Frailty in older adults: a nationally representative profile in the United States. J Gerontol A Biol Sci Med Sci. 2015;70(11):1427-34.

81. Bilotta C, Nicolini P, Case A, et al. Frailty syndrome diagnosed according to the Study of Osteoporotic Fractures (SOF) criteria and adverse health outcomes among community-dwelling older outpatients in Italy. A one-year prospective cohort study. Arch Gerontol Geriatr. 2012;54(2):e23-e28.

82. Studenski S, Perera S, Wallace D, et al. Physical performance measures in the clinical setting. J Am Geriatr Soc. 2003;51(3):314-22.

83. Hoover M, Rotermann M, Sanmartin C, et al. Validation of an index to estimate the prevalence of frailty among communitydwelling seniors. Health Rep. 2013;24(9):10-17.

84. McNallan SM, Singh M, Chamberlain AM, et al. Frailty and healthcare utilization among patients with heart failure in the community. JACC: Heart Failure. 2013;1(2):135-41.

85. McAdams-DeMarco MA, Law A, Salter ML, et al. Frailty as a novel predictor of mortality and hospitalization in individuals of all ages undergoing hemodialysis. J Am Geriatr Soc. 2013;61(6):896-901.

86. Hogan DB, Freiheit EA, Strain LA, et al. Comparing frailty measures in their ability to predict adverse outcome among older residents of assisted living. BMC Geriatr. 2012;12:56.

87. Wou F, Gladman JRF, Bradshaw L, et al. The predictive properties of frailty-rating scales in the acute medical unit. Age Ageing. 2013;42(6):776-81.
88. Sourial N, Bergman H, Karunananthan S, et al. Implementing frailty into clinical practice: a cautionary tale. J Gerontol A Biol Sci Med Sci. 2013;68(12):1505-11.

89. Kiely DK, Cupples A, Lipsitz LA. Validation and comparison of 2 frailty indexes: The MOBILIZE Boston Study. J Am Geriatr Soc. 2009;57(9):1532-39.

90. Forti P, Rietti E, Pisacane N, et al. A comparison of frailty indexes for prediction of adverse health outcomes in an elderly cohort. Arch Gerontol Geriatr. 2012;54(1):16-20.

91. Ekerstad N, Swahn E, Janzon M, et al. Frailty is independently associated with short-term outcomes for elderly patients with non-ST-segment elevation myocardial infraction. Circulation. 2011;124:2397-404.

92. Dasgupta M, Rolfson D, Stolee P, et al. Frailty is associated with postoperative complications in older adults with medical problems. Arch Gerontol Geriatr. 2009;48(1):78-83.

93. Robinson TN, Eiseman B, Wallace JI, et al. Redefining geriatric postoperative assessment using frailty, disability and co-morbidity. Ann Surg. 2009;250(3):449-55.

94. Robinson TN, Wallace JI, Wu DS, et al. Accumulated frailty characteristics predict postoperative discharge institutionalization in the geriatric patient. J Am Coll Surg. 2011;213(1):37-44.

95. Robinson TN, Wu DS, Stiegmann GV, et al. Frailty predicts increased hospital and six-month healthcare costs following colorectal surgery in older adults. Am J Surg. 2011;202(5):511-14.

96. Basic D, Shanley C: Frailty in an older inpatient population: using the clinical frailty scale to predict patient outcomes. $J$ Aging Health. 2015;27(4):670-85.

97. Wallis SJ, Wall J, Biram RWS, et al. Association of the clinical frailty scale with hospital outcomes. QJM. 2015;108(12):94349. Epub 2015 March 16.

98. Kahlon S, Pederson J, Majumdar SR, et al. Association between frailty and 30-day outcomes after discharge from hospital. CMAJ. 2015;187(11):799-804.

99. Inouye SK. Delirium in older persons. $N$ Engl J Med. 2006;354:1157-65.

100. Pol RA, van Leeuwen BL, Visser L, et al. Standardized frailty indicator as predictor for postoperative delirium after vascular surgery: a prospective cohort study. Eur J Vasc Endovasc Surg. 2011;42(6):824-30.

101. Leung JM, Tsai TL, Sands LP. Preoperative frailty in older surgical patients is associated with early postoperative delirium. Anesth Analg. 2011;112(5):1199-201.

102. Andrew MK, Freter SH, Rockwood K. Incomplete functional recovery from delirium in elderly people: a prospective cohort study. BMC Geriatr. 2005;5:5.

103. Joosten E, Demuynck M, Detroyer E, et al. Prevalence of frailty and its ability to predict in hospital delirium, falls, and 6-month mortality in hospitalized older patients. BMC Geriatr. 2014; 14:1.

104. Jung P, Pereira MA, Hiebert B, et al. The impact of frailty on postoperative delirium in cardiac surgery patients. $J$ Thorac Cardiovasc Surg. 2015;149(3): 869-75. 
105. Quinlan N, Marcantonio ER, Inouye SK, et al. Vulnerability: the crossroads of frailty and delirium. $J$ Am Geriatr Soc. 2011;59(Suppl 2):S262-S268.

106. Covinsky KE, Pierluissi E, Johnston CB. Hospitalization-associated disability - "She was probably able to ambulate, but I'm not sure." JAMA. 2011;306(16):1782-93.

107. Boyd CM, Xue Q-L, Simpson CF, et al. Frailty, hospitalization, and progression of disability in a cohort of disabled older women. Am J Med. 2005;118(11):1225-31.

108. Boyd CM, Ricks M, Fried LP, et al. Functional decline and recovery of activities of daily living among hospitalized, disabled older women: The Women's Health and Aging Study. $J$ Am Geriatr Soc. 2009;57(10):1757-66.

109. Carlson JE, Zocchi KA, Bettencourt DM, et al. Measuring frailty in the hospitalized elderly: concept of functional homeostasis. Am J Phys Med Rehabil. 1998;77(3):252-57.

110. Rozzini R, Sabatini T, Cassinadri A, et al. Relationship between functional loss before hospital admission and mortality in elderly persons with medical illness. J Gerontol A Med Sci. 2005;60(9):1180-83.

111. Hubbard RE, Eeles EMP, Rockwood MRH, et al. Assessing balance and mobility to track illness and recovery in older inpatients. J Gen Intern Med. 2011;26(12):1471-78.

112. Joyce MF, Gupta A, Azocar RJ. Acute trauma and multiple injuries in the elderly population. Curr Opin Anesthesiol. 2015;28(2):145-50.

113. Joseph B, Pandit V, Rhee $\mathrm{P}$, et al. Predicting hospital discharge disposition in geriatric trauma patients: is frailty the answer? $J$ Trauma Acute Care Surg. 2014;76(1):196-200.

114. Joseph B, Pandit V, Zangbar B, et al. Superiority of frailty over age in predicting outcomes among geriatric trauma patients - a prospective analysis. JAMA Surg. 2014;149(8):766-72.

115. Joseph B, Pandit V, Zangbar B, et al. Validating trauma-specific frailty index for geriatric trauma patients: a prospective analysis. $J$ Am Coll Surg. 2014;219(1):10-18.

116. Joseph B, Pandit V, Khalil M, et al. Managing older adults with ground-level falls admitted to a trauma service: the effect of frailty. J Am Geriatr Soc. 2015; 63(4):745-49.

117. Bagshaw SM, Webb SA, Delaney A, et al. Very old patients admitted to intensive care in Australia and New Zealand: a multi-centre cohort analysis. Crit Care. 2009;13:R45.

118. Heyland DK, Garland A, Bagshaw SM, et al. Recovery after critical illness in patients aged 80 years or older: a multi-center prospective observational cohort study. Intensive Care Med. 2015;41(11):1911-20.

119. McDermid RC, Bagshaw SM. ICU and critical care outreach for the elderly. Best Pract Res Clin Anaesthesiol. 2011;25(3):439-49.

120. Bagshaw SM, Stelfox T, McDermid RC, et al. Association between frailty and short- and long-term outcomes among critically ill patients: a multicenter prospective cohort study. CMAJ. 2014;186(2):E95-E102.

121. Le Maguet P, Roquilly A, Lasocki S, et al. Prevalence and impact of frailty on mortality in elderly ICU patients: a prospective, multicenter, observational study. Intensive Care Med. 2014;40(5):674-82.
122. Zeng A, Song Z, Dong J, et al. Mortality in relation to frailty in patients admitted to a specialized geriatric intensive care unit. J Gerontol A Biol Sci Med Sci. 2015;70(12):1586-94.

123. McDermid RC, Bagshaw SM. Scratching the surface: the burden of frailty in critical care. Intensive Care Med. 2014;40(5):740-42.

124. Robinson TN, Walston JD, Brummel NE, et al. Frailty for surgeons: review of a National Institute on Aging Conference on Frailty for Specialists. J Am Coll Surg. 2015;221(6):1083-92. Epub 2015 September 11.

125. Kim S, Han H, Jung H, et al. Multidimensional frailty score for the prediction of postoperative mortality risk. JAMA Surg. 2014;149(7):633-40.

126. Revenig LM, Canter DJ, Kim S, et al. Report of a simplified frailty score predictive of short-term postoperative morbidity and mortality. J Am Coll Surg. 2015;220(5):904-11.

127. Balducci L, Extermann M. Management of the frail older person with advanced cancer. Crit Rev Oncol Hematol. 2000;33(2):143-48

128. Mohile SG, Xian Y, Dale W, et al. Association of a cancer diagnosis with vulnerability and frailty in older medicare beneficiaries. J Natl Cancer Inst. 2009;101(17):1206-15.

129. Argilés JM, Busquets S, Stemmler B, et al. Cachexia and sarcopenia: mechanisms and potential targets for intervention. Curr Opin Pharmacol. 2015;22:100-06.

130. Bowen TS, Schuler G, Adams V. Skeletal muscle wasting in cachexia and sarcopenia: molecular pathophysiology and impact of exercise training. J Cachexia Sarcopenia Muscle. 2015;6(3):197-207.

131. Ness KK, Krull KR, Jones KE, et al. Physiologic frailty as a sign of accelerated aging among adult survivors of childhood cancer: a report from the St Jude Lifetime Cohort Study. J Clin Oncol. 2013;31(30):4496-503.

132. Puts MTE, Monette J, Girre V, et al. Does frailty predict hospitalization, emergency department visits, and visits to the general practitioner in older newly-diagnosed cancer patients? Results of a prospective pilot study. Crit Rev Oncol Hematol. 2010;76(2):142-51.

133. Puts MTE, Monette J, Girre V, et al. Are frailty markers useful for predicting treatment toxicity and mortality in older newly diagnosed cancer patients? Results from a prospective pilot study. Crit Rev Oncol Hematol. 2011;78(2):138-49.

134. Sündermann S, Dademasch A, Praetorius J, et al. Comprehensive assessment of frailty for elderly high-risk patients undergoing cardiac surgery. Eur J Cardiothorac Surg. 2011;39(1):33-37.

135. Sündermann S, Dademasch A, et al. One-year follow-up of patients undergoing elective cardiac surgery assessed with the Comprehensive Assessment of Frailty test and its simplified form. Interact Cardiovasc Thorac Surg. 2011;13(2):119-23; discussion 123.

136. Myers V, Drory Y, Gerber Y. Clinical relevance of frailty trajectory post myocardial infarction. Eur J Prev Cardiol. 2014;21(6):758-66.

137. Arnold JMO, Howlett JG, Dorian P, et al: Canadian Cardiovascular Society Consensus Conference recommendations 
on heart failure update 2007: prevention, management during intercurrent illness or acute decompensation, and use of biomarkers. Can J Cardiol. 2007;23(1):21-45.

138. Singh M,Alexander K, Roger VL, et al. Frailty and its potential relevance to cardiovascular care. Mayo Clin Proc. 2008;83(10):1146-53.

139. Afilalo J, Alexander KP, Mack MJ, et al. Frailty assessment in the cardiovascular care of older adults. $J$ Am Coll Cardiol. 2014;63(8):747-62.

140. Walker SR, Gill K, Macdonald K, et al. Association of frailty and physical function in patients with non-dialysis CKD: a systematic review. BMC Nephrology. 2013;14:228.

141. Bao Y, Dalrymple L, Chertkow GM, et al. Frailty, dialysis initiation, and mortality in end-stage renal disease. Arch Intern Med. 2012;172(14):1071-77.

142. Berger JR, Hedayati SS. When is a conservative approach to advanced chronic kidney disease preferable to renal replacement therapy? Sem Dialysis. 2014;27(3):253-56.

143. McAdams-DeMarco MA, Isaacs K, Darko L, et al. Changes in frailty after kidney transplantation. $J$ Am Geriatr Soc. 2015;63(10):2152-57.

144. Buttery AK, Busch MA, Gaertner B, et al. Prevalence and correlates of frailty among older adults: findings from the German health interview and examination survey. BMC Geriatr. 2015;15:22.

145. Crentsil V, Ricks MO, Xue Q-L, et al. A pharmacoepidemiologic study of community-dwelling, disabled older women: factors associated with medication use. Am J Geriatr Pharmacother. 2010;8(3):215-24.

146. Gnjidic D, Hilmer SN, Blyth FM, et al. High-risk prescribing and incidence of frailty among older community-dwelling men. Clin Pharmacol Ther. 2012;91:521-28.

147. Runganga M, Peel NM, Hubbard RE. Multiple medication use in older patients in post-transitional care: a prospective cohort study. Clin Interv Aging. 2014;9:1453-62.

148. Peklar J, O'Halloran AM, Maidment ID, et al. Sedative load and frailty among community-dwelling population aged $\geq 65$ years. J Am Med Dir Assoc. 2015;16(4):282-89.

149. Moulis F, Moulis G, Balrady L, et al. Exposure to atropinic drugs and frailty status. J Am Med Dir Assoc. 2015;16(3):253-57.

150. Bennett A, Gnjidic D, Gillett M, et al. prevalence and impact of fall-risk-increasing drugs, polypharmacy, and drug-drug interactions in robust versus frail hospitalized falls patients: a prospective cohort study. Drugs Aging. 2014;31(3):225-32.

151. Lakey SL, LaCroix AZ, Gray SL, et al. Antidepressant use, depressive symptoms, and incident frailty in women aged 65 and older from the Women's Health Initiative Observational Study. J Am Geriatr Soc. 2012;60(5):854-61.

152. Wynne HA, Cope LH, Herd B, et al. The association of age and frailty with paracetamol conjugation in man. Age Ageing. 1990;19(6):419-24.

153. Wynne HA, Yelland C, Cope LH, et al. The association of age and frailty with the pharmacokinetics and pharmacodynamics of metoclopramide. Age Ageing. 1993;22(5):354-59.

154. Hubbard RE, O’Mahony MS, Calver BL, et al. Plasma esterases and inflammation in ageing and frailty. Eur J Clin Pharmacol. 2008;64:895-900.
155. McLachlan AJ, Bath S, Naganathan V, et al. Clinical pharmacology of analgesic medicines in older people: impact of frailty and cognitive impairment. Br J Clin Pharmacol. 2011;71(3):351-64.

156. Hubbard RE, O'Mahony MS, Woodhouse KW. Medication prescribing in frail older people. Eur J Clin Pharmacol. 2013;69(3):319-26.

157. Johnston C, Hilmer SN, McLachlan AJ, et al. The impact of frailty on pharmacokinetics in older people: using gentamicin population pharmacokinetic modeling to investigate changes in renal drug clearance by glomerular filtration. Eur J Clin Pharmacol. 2014;70(5):549-55.

158. Warwick J, Falaschetti E, Rockwood K, et al. No evidence that frailty modifies the positive impact of antihypertensive treatment in very elderly people: an investigation of the impact of frailty upon treatment effect in the HYpertension in the Very Elderly Trial (HYVET) study, a double-blind, placebo-controlled study of antihypertensives in people with hypertension aged 80 and over. BMC Med. 2015;13:78.

159. Perera V, Bajorek BV, Matthews S, et al. The impact of frailty on the utilisation of antithrombotic therapy in older patients with atrial fibrillation. Age Ageing. 2009;38(2):156-62.

160. Tay KH, Lane DA, Lip GYP. Challenges facing anticoagulation among the elderly and frail. Age Ageing. 2009;38(2):140-42.

161. Campbell S, Szoeke C. Pharmacological treatment of frailty in the elderly. J Pharm Pract Res. 2009;39(2):147-51.

162. Jeffery CA, Shum DWC, Hubbard RE. Emerging drug therapies for frailty. Maturitas. 2013;74(1):21-25.

163. Boockvar KS, Meier DE. Palliative care for frail older adults. JAMA. 2006;296:2245-53.

164. Turner NJ, Howard RA, Mulley GP, et al. Cancer in old age - is it adequately investigated and treated. BMJ. 1999;319(7205):309-12.

165. Maida V, Devlin M. Frailty, thy name is Palliative! CMAJ. 2015; 187(17):1312.

166. Mallery LH, Moorhouse P. Respecting frailty. J Med Ethics. 2011;37(2):126-28.

167. Pacala JT, Boult C, Boult L. Predictive validity of a questionnaire that identifies older persons at risk for hospital admission. J Am Geriatr Soc. 1995;43(4):374-77.

168. ASA Physical Status Classification System. Schaumberg, IL: Am. Soc. Anesthesologists. 2015. Accessed November 26, 2015. Available from: https://www.asahq.org/resources/ clinical-information/asa-physical-status-classificationsystem

169. Pijpers E, Ferreira I, Stehouwer CDA, et al. The frailty dilemma. Review of the predictive accuracy of major frailty scores. Eur J Intern Med. 2012;23(2):118-23.

170. Rodriguez-Mañas L, Fried LP. Frailty in the clinical scenario. Lancet. 2015;385(9968):e7-e29.

171. Aarts S, Patel KV, Garcia ME, et al. Co-presence of multimorbidity and disability with frailty: an examination of heterogeneity in the frail older population. J Frailty Aging. 2015;4:131-38.

172. Ferrante LE, Pisani MA, Murphy TE, et al. Functional trajectories among older persons before and after critical illness. JAMA Intern Med. 2015;175(4):523-29. 
173. Hogan DB. Current understanding of the concept of frailty in later life. Aging Health. 2007;3(6):767-77.

174. Ellis G, Whitehead MA, Robinson D, et al. Comprehensive geriatric assessment for older adults admitted to hospital: meta-analysis of randomized controlled trials. $B M J$. 2011;343:d6553.

175. Bakker FC, Robben SHM, Rikkert MGMO. Effects of hospital-wide interventions to improve care for frail older inpatients: a systematic review. BMJ Qual Saf. 2011;20(8):680-91.

176. Arora VM, Plein C, Chen S, et al. Relationship between quality of care and functional decline in hospitalized vulnerable seniors. Med Care. 2009;47(8):895-901.

177. Zisberg A, Shadmi E, Gur-Yaish N, et al. Hospital-associated functional decline: the role of hospitalization processes beyond individual risk factors. J Am Geriatr Soc. 2015;63(1):55-62.

178. Lafont C, Gérard S, Voisin T, et al. Reducing "iatrogenic" disability in the hospitalized frail elderly. J Nutr Health Aging. 2011;15(8):645-60.

179. Bibas L, Levi M, Bendayan M, et al. Therapeutic interventions for frail elderly patients: Part I. Published randomized trials. Prog Cardiovasc Dis. 2014;57(2):134-43.

180. Bendayan M, Bibas L, Levi M, et al. Therapeutic interventions for frail elderly patients: Part II. Ongoing and unpublished trials. Prog Cardiovasc Dis. 2014;57(2):144-51.

181. Kao H, Walter LC. Improvement of hospital care of elderly patients - thinking outside the (hospital) box. Arch Intern Med. 2009;169(17):1576-77.

182. Shepperd S, Iliffe S, Doll H, et al. Admission avoidance hospital at home. Cochrane Database Syst Rev. 2008; Issue 4: Art. No.: CD007491.

183. Shepperd S, Doll H, Broad J, et al. Hospital at home early discharge. Cochrane Database of Syst Rev. 2009.

184. Young J. The development of intermediate care services in England. Arch Gerontol Geriatr. 2009;49(Supp1 2):S21-S25.
185. Caplan GA, Ward JA, Brennan NJ, et al. Hospital in the home: a randomized controlled trial. Med J Aust. 1999;170(4):156-60.

186. Leff B, Burton L, Mader SL, et al. Hospital at Home: feasibility and outcomes of a program to provide hospital-level care at home for acutely ill older patients. Ann Intern Med. 2005;143(11):798-808.

187. Caplan GA, Coconis J, Board N, et al. Does home treatment affect delirium? A randomised controlled trial of rehabilitation of elderly and are at home or usual treatment (The REACHOUT trial). Age Ageing. 2006;35(1):53-60.

188. Isaia $\mathrm{G}$, Astengo MA, Tibaldi V, et al. Delirium in elderly home-treated patients: a prospective study with 6-month follow-up. Age. 2009;31(2):109-17.

189. Inouye SK, Schlesinger MJ, Lydon TJ. Delirium: a symptom of how hospital care is failing older persons and a window to improve quality of hospital care. Am J Med. 1999;106(5):565-73.

190. Svanborg A. How aging related frailty will influence the quality of care results from a 15-year follow-up of 70-year-old people in Gothenburg, Sweden. Int J Quality Health Care. 1990;2(3/4):403-09.

191. Rockwood K, Theou O, Mitnitski A. What are frailty instruments for? Age Ageing. 2015;44(5):545-47.

192. Dent E, Hoogendijik EO. Psychosocial factors modify the association of frailty with adverse outcomes: a prospective study of hospitalised older people. BMC Geriatr. 2014;14:108.

Correspondence to: Colleen J. Maxwell, PhD, Schools of Pharmacy and Public Health \& Health Systems, University of Waterloo, 200 University Ave W., Waterloo, ON N2L 3G1, Canada

E-mail: colleen.maxwell@uwaterloo.ca 


\section{APPENDICES}

Appendix A: Attendees of invitational expert consultation CIHR planning meeting on Frailty in Acute Care held May 2-3, 2014 in Banff, Alberta.

Dr. Jonathan Afilalo (McGill University)

Dr. Rakesh C. Arora (University of Manitoba)

Dr. Sean M. Bagshaw (University of Alberta)

Dr. Jenny Basran (University of Saskatchewan)

Dr. Howard Bergman (McGill University)

Dr. Susan Bronskill (Institute for Clinical Evaluative Sciences)

Ms. Sima Gandhi (Institute for Clinical Evaluative Sciences)

Dr. Brenda Hemmelgarn (University of Calgary)

Dr. David B. Hogan (University of Calgary)

Dr. Kenneth Madden (University of British Columbia)

Dr. Tina Mah (Grand River Hospital)

Dr. Colleen J. Maxwell (University of Waterloo)

Dr. Arnold Mitnitski (Dalhousie University)

Dr. Darryl Rolfson (University of Alberta)

Ms. Kathryn J. Stock (Graduate Student)

Ms. Helen Tam-Tham (Graduate Student)

Dr. Hannah Wunsch (University of Toronto)

Invited consultants not able to attend:

Dr. Elijah Dixon (University of Calgary)

Dr. H. Tom Stelfox (University of Calgary)

Appendix B: Search terms \& strategy.

1. PubMed Search

(((frail elderly[MeSH Terms]) OR ((frail[tiab] OR frailty[tiab])

AND (middle age*[tiab] OR “middle aged"[MeSH Terms]

OR aged[tiab] OR “aged"[MeSH Terms] OR “aged, 80 and over"[MeSH Terms] OR elder*[tiab] OR seniors[tiab] OR geriatric*[tiab] OR gerontolog*[tiab] OR “older age"[tiab] OR “older people"[tiab] OR “older person" [tiab] OR “older men"[tiab] OR “older women"[tiab]))) AND ((“acute care”[tiab] OR acute[tiab] OR hospital[tiab] OR hospitals[tiab] OR “hospitals"[MeSH Terms] OR hospitalization[tiab] OR hospitalisation[tiab] OR “hospitalization”[MeSH Terms] OR inpatient*[tiab] OR “inpatients"[MeSH Terms] OR “emergency service, hospital'"[MeSH Terms] OR emergency department* [tiab] OR emergency room*[tiab] OR emergency center*[tiab] OR emergency centre*[tiab] OR emergency ward*[tiab] OR “emergency care"[tiab]))) NOT ((“Animals"[MeSH Terms] NOT "Humans"[MeSH Terms])) AND English[lang] Filters: Publication date from 2005/01/01 to 2015/12/31

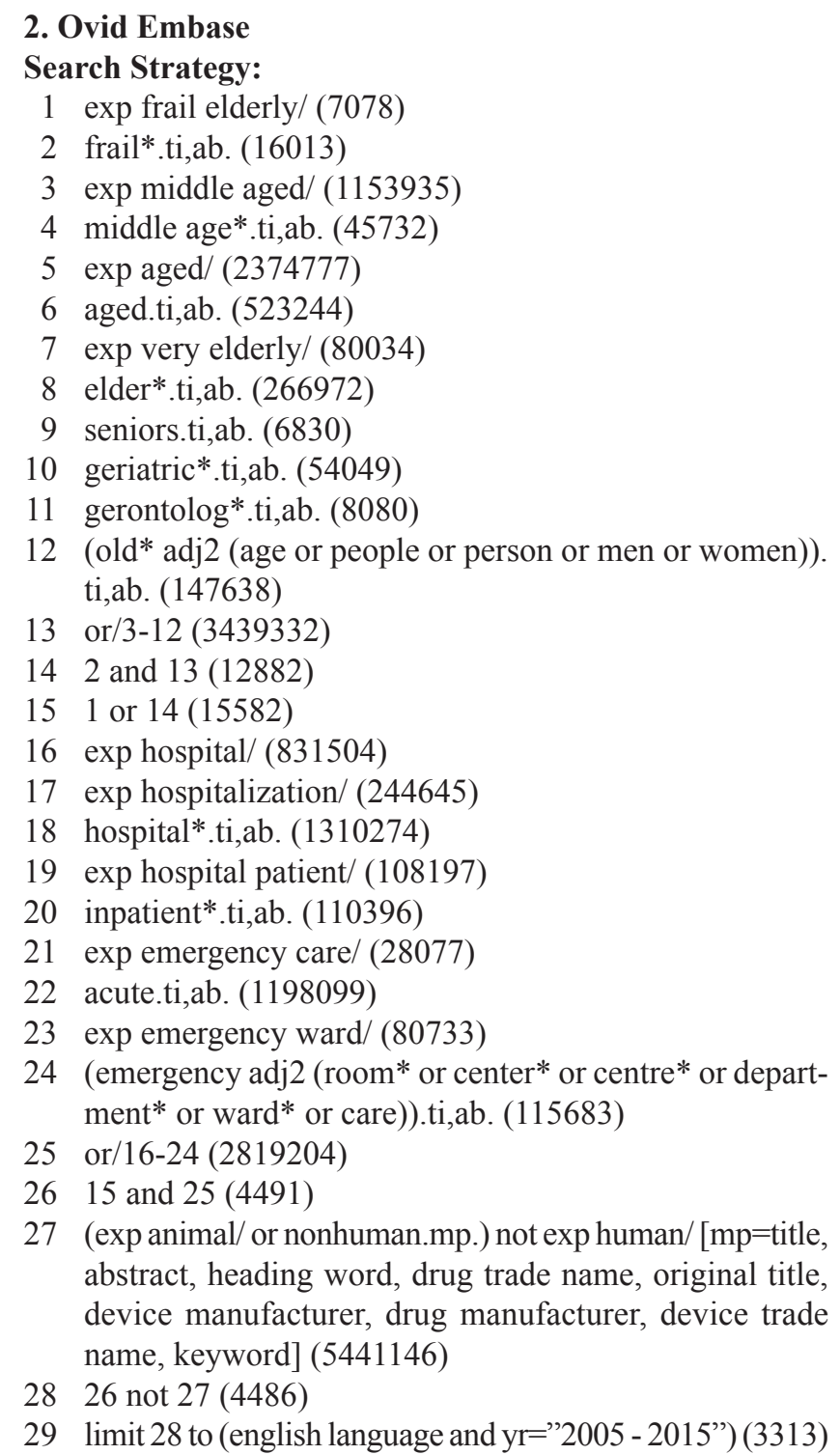

